\title{
TU/e EmonOWEN

\section{Superabsorbent polymers to mitigate plastic drying shrinkage in a cement paste as studied by NMR}

\section{Citation for published version (APA):}

Snoeck, D., Pel, L., \& De Belie, N. (2018). Superabsorbent polymers to mitigate plastic drying shrinkage in a cement paste as studied by NMR. Cement \& Concrete Composites, 93, 54-62.

https://doi.org/10.1016/j.cemconcomp.2018.06.019

\section{Document license: \\ TAVERNE}

DOI:

10.1016/j.cemconcomp.2018.06.019

Document status and date:

Published: 01/10/2018

\section{Document Version:}

Publisher's PDF, also known as Version of Record (includes final page, issue and volume numbers)

\section{Please check the document version of this publication:}

- A submitted manuscript is the version of the article upon submission and before peer-review. There can be important differences between the submitted version and the official published version of record. People interested in the research are advised to contact the author for the final version of the publication, or visit the $\mathrm{DOI}$ to the publisher's website.

- The final author version and the galley proof are versions of the publication after peer review.

- The final published version features the final layout of the paper including the volume, issue and page numbers.

Link to publication

\section{General rights}

Copyright and moral rights for the publications made accessible in the public portal are retained by the authors and/or other copyright owners and it is a condition of accessing publications that users recognise and abide by the legal requirements associated with these rights.

- Users may download and print one copy of any publication from the public portal for the purpose of private study or research.

- You may not further distribute the material or use it for any profit-making activity or commercial gain

- You may freely distribute the URL identifying the publication in the public portal.

If the publication is distributed under the terms of Article 25fa of the Dutch Copyright Act, indicated by the "Taverne" license above, please follow below link for the End User Agreement:

www.tue.nl/taverne

Take down policy

If you believe that this document breaches copyright please contact us at:

openaccess@tue.nl

providing details and we will investigate your claim. 


\title{
Superabsorbent polymers to mitigate plastic drying shrinkage in a cement paste as studied by NMR
}

\author{
D. Snoeck ${ }^{\mathrm{a}, \mathrm{b}, *}$, L. Pel $^{\mathrm{b}}$, N. De Belie ${ }^{\mathrm{a}}$ \\ ${ }^{a}$ Magnel Laboratory for Concrete Research, Department of Structural Engineering, Faculty of Engineering and Architecture, Ghent University, Tech Lane Ghent Science \\ Park, Campus A, Technologiepark Zwijnaarde 904, B-9052, Gent, Belgium \\ ${ }^{\mathrm{b}}$ Transport in Permeable Media, Department of Applied Physics, Eindhoven University of Technology, Eindhoven, the Netherlands
}

\section{A R T I C L E I N F O}

\section{Keywords:}

Hydration

Shrinkage

Cement paste

Hydrogels

NMR

\begin{abstract}
A B S T R A C T
At early ages, a problem of plastic shrinkage can arise when a cement paste is subjected to harsh drying conditions during hardening. SuperAbsorbent Polymers (SAPs) are a promising admixture to mitigate shrinkage in cement pastes. By introducing internal curing by means of the stored mixing water in the SAPs, the plastic shrinkage can be partially mitigated, next to the mitigation of autogenous shrinkage during setting of the cement paste. The kinetics of water release by the SAPs towards the cementitious matrix have been studied in detail to understand the mechanism. Nuclear Magnetic Resonance (NMR) is an effective technique to non-destructively monitor the effects induced by the SAPs during this plastic period and hardening as a function of time. The SAPs are able to protect the cement paste internally from the harsh ambient drying conditions and are able to sustain the internal relative humidity. The plastic settlement was reduced and there was less plastic shrinkage measured. Below $5 \mathrm{~mm}$ of the surface in SAP specimens, the specimens were hardening as if put in sealed conditions.
\end{abstract}

\section{Introduction}

SuperAbsorbent Polymers (SAPs) are able to absorb several hundred to thousand times their own weight in fluids and to retain it within their structure. After application in the medical and hygiene industry [1], it was only a matter of time till this material was also applied in a cementitious material [2] to change the rheology [3], to increase the freeze-thaw resistance [4,5], to induce self-sealing [6-9] and selfhealing [10-14]. Furthermore, a cement paste with a low water-tobinder ratio experiences high autogenous shrinkage deformation after it has set due to the occurring cement hydration. SAPs have therefore been proposed as an admixture to mitigate this self-desiccation and autogenous shrinkage [15-18].

However, shrinkage may also occur during the first hours after casting while the cement paste is still plastic and when it shows no significant strength development [19]. The cause of this plastic shrinkage is the (rapid) evaporation of water near the surface leading to high capillary pressures as water menisci begin to develop in between the solid particles [20]. This causes capillary tension among the solid particles and thus settlement and shrinkage. At some point, the water menisci disappear and air will flow in between the particles [21]. If the specimen deformation is restrained, it may crack [22].
Only a limited amount of studies have investigated the influence of SAPs in terms of plastic shrinkage mitigation. Dudziak and Mechtcherine investigated the influence of SAPs on the plastic behaviour of fresh cement pastes with a water-to-cement ratio of 0.265 [23]. They used a spherical SAP with an average size of approximately $150 \mu \mathrm{m}$ in the dry state. The amount of entrained water by adding $0.6 \mathrm{~m}$ $\%$ of SAP by cement weight corresponded to an additional water-tocement factor of 0.087. Dudziak and Mechtcherine found that the capillary pressure and the plastic deformations were reduced in the SAP mixtures, but the settlement deformation increased compared to reference samples with a water-to-cement ratio of 0.265 [23].

The SAPs retain their stored entrained water within water-filled macro-pore inclusions in the cementitious material. In that way, they are able to reduce self-desiccation shrinkage by internal curing and may possibly aid in mitigating plastic shrinkage as well. It is difficult to study the effect of SAPs without destructing the microstructure. Nuclear Magnetic Resonance (NMR), however, is a non-destructive technique to study the water amounts $\left({ }^{1} \mathrm{H}\right)$ in a material. It is a powerful technique to study the cement hydration and the fluid transport in porous materials [24-26]. The hydrogen atoms interacts with the pore wall and a result the NMR signal will decay. The resulting relaxation rate is proportional to the pore structure and can be quantified [27]. Friedemann et al.

\footnotetext{
* Corresponding author. Magnel Laboratory for Concrete Research, Department of Structural Engineering, Faculty of Engineering and Architecture, Ghent University, Tech Lane Ghent Science Park, Campus A, Technologiepark Zwijnaarde 904, B-9052, Gent, Belgium.

E-mail addresses: didier.snoeck@UGent.be (D. Snoeck), nele.debelie@UGent.be (N. De Belie).
} 
showed that water is available during post-internal curing of cement pastes, when most of the internal curing already took place [28]. Nestle et al. used NMR to study the water balance in a cement paste with SAPs [29]. NMR is thus a feasible technique to investigate the water states in cement pastes with SAPs.

The type and size of the polymers are important. If the SAP is releasing its water too fast due to a low resistance to capillary forces, i.e. before final setting, the total water-to-cement ratio would increase. This may cause the cementitious matrix to have inferior properties [30,31]. On the other hand, when it would be releasing its water too slow, the water is not available for curing. The SAPs thus need to release their water at the right moment in time. The SAPs also need to be homogenously distributed. The most ideal swollen SAP size for mitigating autogenous shrinkage is $100-200 \mu \mathrm{m}$ [15]. Too big SAPs would not be able to cure the complete cementitious matrix at the same amount. In this study, a small SAP with dry size of approximately $100 \mu \mathrm{m}$ used to mitigate autogenous shrinkage [17] will be used. This SAP will be compared to a bigger SAP with a size of approximately $480 \mu \mathrm{m}$. This latter SAP is ideal to self-seal and self-heal a crack [9,14]. The bigger SAP was, as expected, inferior to the smaller SAP to mitigate autogenous shrinkage and to maintain the internal relative humidity $[17,32]$. A previous NMR study of the respective SAPs revealed that the smaller SAP gradually releases its stored water after time of final setting, ideally maintaining the internal relative humidity [32]. The larger SAP prematurely released its stored water after time of final setting, leading to an inferior internal curing compared to the smaller SAP [32]. However, this polymer may behave differently upon plastic shrinkage and was thus also included in the current study.

Plastic shrinkage may lead to different timing of water release by the SAPs and is therefore subject of this study. The water near the top surface may be released before setting or may act as a buffer zone. In this paper, the curing by the SAPs during plastic shrinkage and the change in water states as a function of time are monitored by means of NMR tests. NMR was used for the first time to study the SAPs' water release and kinetics as a function of time.

\section{Materials and methods}

In this section, the different studied mixtures and types of SAP are explained first (2.1), followed by the NMR apparatus and principle (2.2). In the end, thin-section analysis is explained (2.3).

\subsection{Studied mixture compositions}

Two reference cement pastes with a water-to-binder ratio (W/B) of 0.3 (R0.30) and 0.354 (R0.354), respectively, were made. The cement used was a CEM I $52.5 \mathrm{~N}$ Portland type. Superplasticizer was added in an amount of $0.5 \mathrm{~m} \%$ and $0.3 \mathrm{~m} \%$ (mass- $\%$ of cement weight) to ensure practical workability for the R0.30 and R0.354 mixture. The superplasticizer used was a polycarboxylate type (Glenium 51, conc. 35\%, BASF).

Based on the model of Powers and Brownyard [33], the amount of needed entrained water in the SAPs for internal curing of the reference paste with a water-to-cement ratio of 0.30 can be theoretically calculated and amounts to an additional water-to-cement ratio of 0.054 [15]. In that way, the total water-to-cement ratio $(\mathrm{w} / \mathrm{c})_{\text {tot }}$ equals 0.354 , but taking into account that the amount of 0.054 is entrained in the SAPs $(\mathrm{w} / \mathrm{c})_{\mathrm{e}}$ it leads to an effective water-to-cement ratio $(\mathrm{w} / \mathrm{c})_{\text {eff }}$ of 0.30 . Two different mixtures containing different SAPs (BASF) were investigated. These were SAP A (for mixture $\mathbf{A}_{\mathbf{e}}$ ), a copolymer of acrylamide and sodium acrylate (particle size $100.0 \pm 21.5 \mu \mathrm{m}(\mathrm{n}=100)$ ), and SAP B (for mixture $\mathbf{B}_{\mathbf{e}}$ ), a cross-linked potassium salt polyacrylate (particle size $476.6 \pm 52.9 \mu \mathrm{m}(\mathrm{n}=100)$ ). Both SAPs are bulk-polymerized and consist of irregular crushed particles. They were stored in dry and sealed conditions prior to testing or mixing in the cement paste mixture. SAP A is able to absorb $305 \pm 4 \mathrm{~g} / \mathrm{g}$ SAP in demineralized water and $61 \pm 1 \mathrm{~g} / \mathrm{g}$ SAP in cement filtrate solution and has a swelling time of $10 \mathrm{~s}[14,17]$. SAP B absorbs $283 \pm 2 \mathrm{~g} / \mathrm{g}$ SAP in demineralized water and $58 \pm 2 \mathrm{~g} / \mathrm{g}$ SAP in cement filtrate solution with a swelling time of $60 \mathrm{~s}[14,17]$. The absorption capacity was determined using the filtration method and the swelling time using the vortex method [34]. Both swelling times are fast enough to ensure complete swelling during mixing. In this way, the entrained water is completely absorbed by the SAPs and the $(\mathrm{w} / \mathrm{c})_{\text {eff }}$ is 0.30 .

The following mixing procedure was used. The SAP particles were added on top to the cement and were first dry mixed to ensure a homogenous distribution in the cement. After this dry mixing, the total water was added together with superplasticizer which was dissolved in the water prior to addition. The amount of superplasticizer in the SAP mixtures was the same as for the R0.30 mixture, to minimize possible influences of different amounts of superplasticizer on the setting properties of the respective mixtures [35]. The total amount of water for a water-to-cement ratio of 0.354 was added. The amount of SAP to be added to maintain the same workability as for R0.30 was $0.22 \mathrm{~m} \%$ (mass- $\%$ of binder weight) SAP A (for mixture $A_{e}$ ) and $0.45 \mathrm{~m} \%$ SAP B (for mixture $B_{e}$ ), respectively. These values were obtained by subsequent flow measurements [36] following the Standard EN 12350-5. X-ray computed micro-tomography [13] and microscopic analysis [30] were used to verify whether the formed macro pores had the expected size. No loss in workability because of SAP addition was observed.

A Vicat needle test following the Standard ASTM C191-08 (Method A: Reference Test Method using the manually operated Vicat apparatus) was used to determine the setting times of the mixtures. The time of final setting was defined as the time between initial contact of cement and mixing water and the time at which the needle did not leave a circular impression in the cement paste surface. This time is referred to as the optimal starting time of water release by the SAPs to mitigate autogenous shrinkage and to start internal curing [17].

\subsection{Nuclear Magnetic Resonance (NMR) setup}

Sample containers (cylinder $\varnothing 27 \mathrm{~mm} \times 100 \mathrm{~mm}$ high) were filled with fresh cement paste for approximately $45 \mathrm{~mm}$ and put in the NMR setup as shown in Fig. 1. Furthermore, dry air was blown over the top of the specimen in such a way that the evaporation rate exceeded $1 \mathrm{~kg}$ per square meter per hour, as in that way plastic shrinkage will likely develop (ASTM Standard C1579-06). This was verified using several dummy tests on the same mixtures and with water samples prior to testing with NMR. Different air inlet flows were used until the required evaporation rate was reached. The mass decrease was measured using a mass scale with precision of $0.001 \mathrm{~g}$. In all tests, the intended evaporation rate was obtained $\left(1.04 \pm 0.02 \mathrm{~kg} / \mathrm{h} / \mathrm{m}^{2}\right)$.

An external magnetic field $\mathrm{B}_{\text {main }}$ of $0.8 \mathrm{~T}$ was applied corresponding to a frequency of $34 \mathrm{MHz}$. This field was provided by a water-cooled iron-cored electromagnet with poles $50 \mathrm{~mm}$ apart from each other. A coil was placed around the sample for creating and receiving the radiofrequency fields. A Faraday shield was added between the coil and the sample to suppress the effect of the changes of the dielectric permittivity by variations of the moisture content, hence making the NMR measurements quantitative. All NMR measurements were performed at room temperature $\left(23 \pm 1{ }^{\circ} \mathrm{C}\right)$.

The magnetic field gradient was set at $0.3 \mathrm{~T} / \mathrm{m}$ offering a one-dimensional resolution in the order of magnitude of $1.0 \mathrm{~mm}$. The intensity of the signal was recorded along the height of the specimen by moving the specimen by means of a step motor (in steps of $1 \mathrm{~mm}$ ). The spinecho signal $\mathrm{S}$ was recorded after an echo time $\mathrm{T}_{\mathrm{E}}$ equal to $180 \mu \mathrm{s}$. CarrPurcell-Meiboom-Gill (CPMG) sequences were measured along the height and the overall total water signal intensity was recorded. Profiles were measured with $44 \mathrm{~min}$ intervals and a total measuring time of $48 \mathrm{~h}$. Fast Laplace Inversion (FLI) was used to obtain the relaxation times $\mathrm{T}_{2}$ as a spectrum [32,37]. All peaks were normalized to the first signal to obtain the percentage. The weighed percentage of each peak 


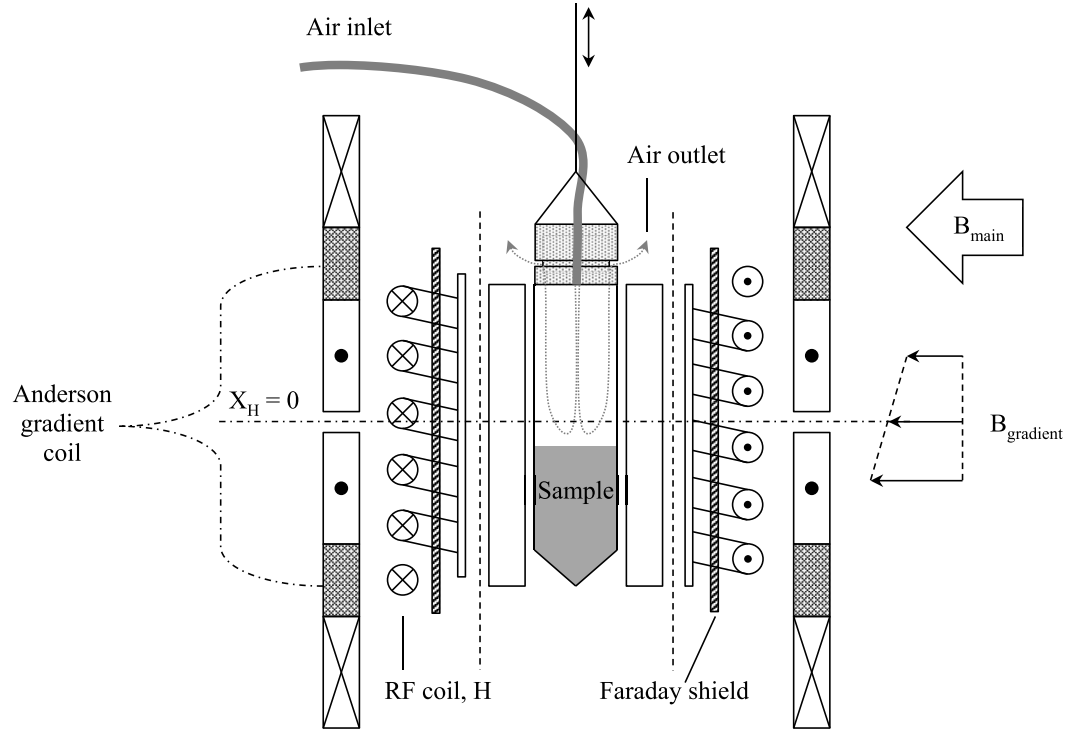

Fig. 1. Sealed sample container (cylinder $\varnothing$ $27 \mathrm{~mm} \times 100 \mathrm{~mm}$ high) filled with the cement paste $(45 \mathrm{~mm})$ mounted with an air in-/outlet. The sample can be moved through the NMR with help of a step motor. The NMR makes use of an electromagnet generating a main magnetic field of $0.8 \mathrm{~T}$. Using Anderson gradients coils a constant gradient is applied of $0.3 \mathrm{~T} / \mathrm{m}$. A Faraday shield has been added to ensure quantitative NMR measurements. was then multiplied with the normalized signal, resulting in the relative ratio of each studied peak as a function of time.

For the SAP-mixtures, a comparison was made between the signal of the SAP entrained water and the free water to investigate when and how the water is released by the SAPs for internal curing. The specimen was studied for $48 \mathrm{~h}$ after water contact with the cement. The first NMR measurement was performed after $10 \mathrm{~min}$ of contact time of water with cement paste.

\subsection{Thin-section and microscopic analysis}

Thin sections (approximately $45 \mathrm{~mm} \times 27 \mathrm{~mm} \times 25 \mu \mathrm{m}$ ) were prepared from studied specimens after being studied with NMR upon plastic shrinkage. First, the specimens were cut to receive $45 \mathrm{~mm} \times 27 \mathrm{~mm}$ faces along the axis of the cylindrical specimen, which were then glued on a glass slide with a thickness of $2.9 \mathrm{~mm}$. The combined sample was cut and polished until a height of the specimen and glass of $10.1 \mathrm{~mm}$ was reached. Next, the specimens were impregnated under vacuum with a fluorescent epoxy. The excess epoxy was polished away and an object glass was glued on the smooth surface. Finally, the glass slides were cut off and the remaining part was polished until a thin section with $25 \mu \mathrm{m}$ thickness was achieved. The epoxy ensured stable handling of the whole specimen. A cover glass was glued on top to protect the thin section.

The thin sections were analysed with a Leica DMLP microscope with a DFC 295 camera. Normal light, polarized light and fluorescent light were used to study the change in microstructure at the exposed drying surface compared to the interior microstructure. Eventual cracking was also studied in detail.

\section{Results and discussion}

NMR was used to obtain the total water signal as a function of the height and time (section 3.1). CPMG measurements were conducted at the same time to study the relative amount of SAP entrained water and free water during hardening. These results are discussed in section 3.2. After NMR testing, the specimens were prepared for thin-section analysis. The effect of the plastic shrinkage on the microstructural change and the crack formation were studied and are discussed in section 3.3.

\subsection{Total water signal distribution and plastic settlement}

The overall total water signal distribution along the height of the specimens is shown in Fig. 2. The top of the specimen exposed to the drying air current is found on the right-hand side. The bottom of the specimen is found on the left-hand side. In time, the curves of the total water signal shift downward as the free water is consumed due to hydration. The change in position of the inflection point in the curve at the surface of the sample exposed to air (right-hand side) served as a basis for the estimation for the plastic settlement. These points are shown as circles $\left({ }^{\circ}\right)$ on the figures. Plastic settlement is seen on the right as the profiles shift to the left due to the moving surface. All inflection points found are depicted on the figure as different drying front conditions may be present. These will be discussed in detail later on. All observed inflection points are shown in the figure, in order to provide a complete picture of drying.

Four distinct regions (zone 1-4) are found when studying the total water profiles. When a cement paste is hardening, the free water will be consumed and hydration products will be formed causing the material to become denser. There generally is a decrease in total water signal over time, i.e. the curves are shifted downwards. Two distinct regions with profiles narrower together are found (zone 2 and 4). The first upper narrow region (zone 2) corresponds with setting. Initial setting occurred at approximately $8 \mathrm{~h}$ of age and final setting was at approximately $11 \mathrm{~h}$ of age as determined with the Vicat needle test, for R0.30, Ae and Be. The setting of R0.354 occurred approximately $1 \mathrm{~h}$ earlier. The lower dense region corresponds with the total consumption of free water due to an increasing degree of hydration in time (zone 4). The specimen becomes hardened. Zone 1 starts at $10 \mathrm{~min}$ of contact with water, zone 2 starts after approximately $4 \mathrm{~h}$ of contact with water and zone 3 after approximately $10 \mathrm{~h}$. Zone 4 starts after approximately $24 \mathrm{~h}$ of contact with water and the test ended after 4 days of measuring, showing the end of zone 4 . In time, the curves would further decrease in value but plastic shrinkage has already occurred.

In the reference samples, the curves show a partial higher decrease in water content near the drying surface (blue region at the right-hand side, especially in the R0.354 mixture). This hints to the harsh drying conditions during hardening. Part of the water is moving towards the drying surface and moisture is lost. As the moisture content is decreasing, the capillary pressure will increase due to receding menisci leading to plastic shrinkage. For the R0.354 sample, the initial total water signal intensity is higher compared to the R0.30 sample due to the higher water-to-cement ratio. The ratio between both signal intensities corresponds to the ratio of both water-to-cement ratios. In the end (bottom curves for R0.354), the water profiles are somewhat tilted, showing that water has been used partially due to plastic shrinkage.

For the SAP samples, the found curves are more or less horizontal, showing the positive aspect of using SAPs for maintaining the internal 


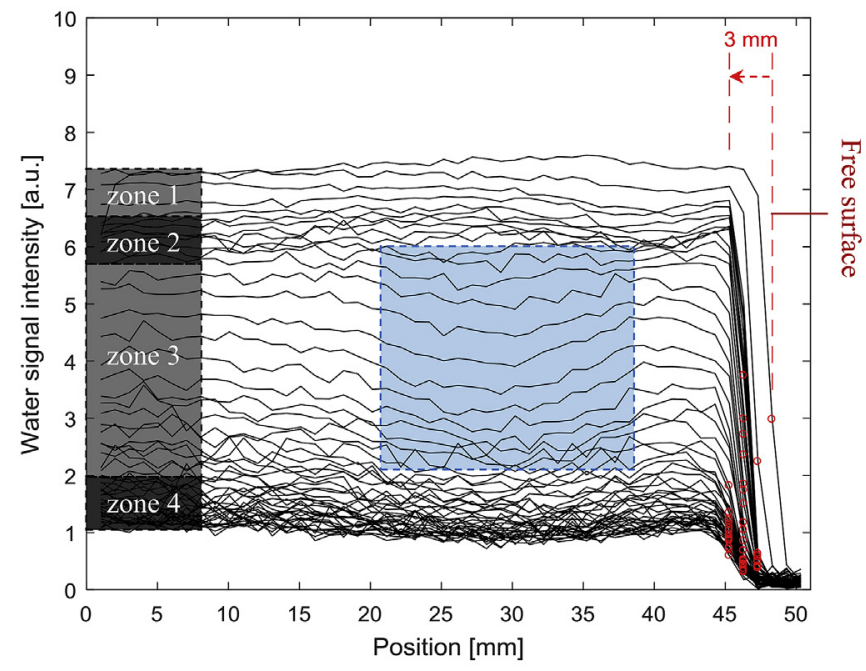

R0.30

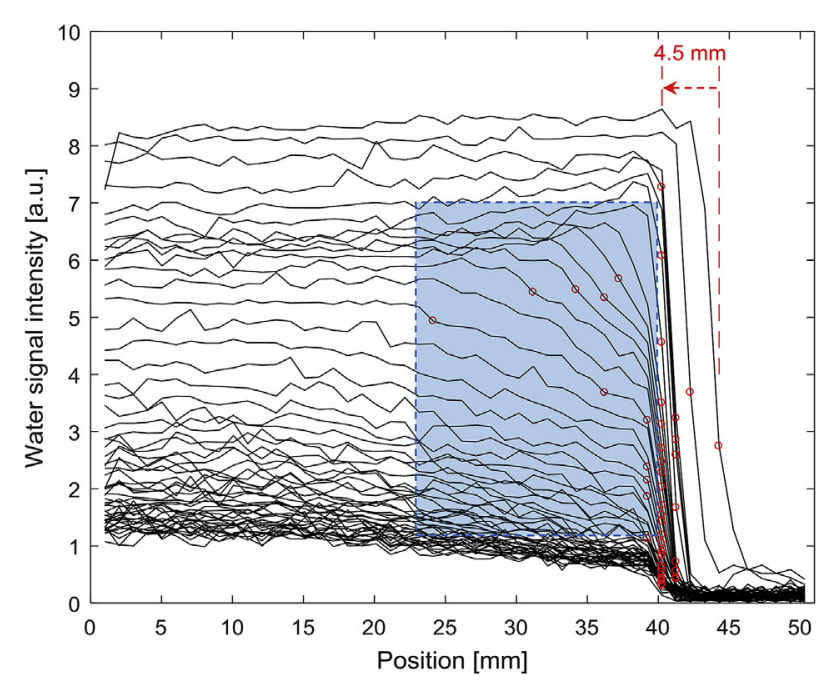

R0.354

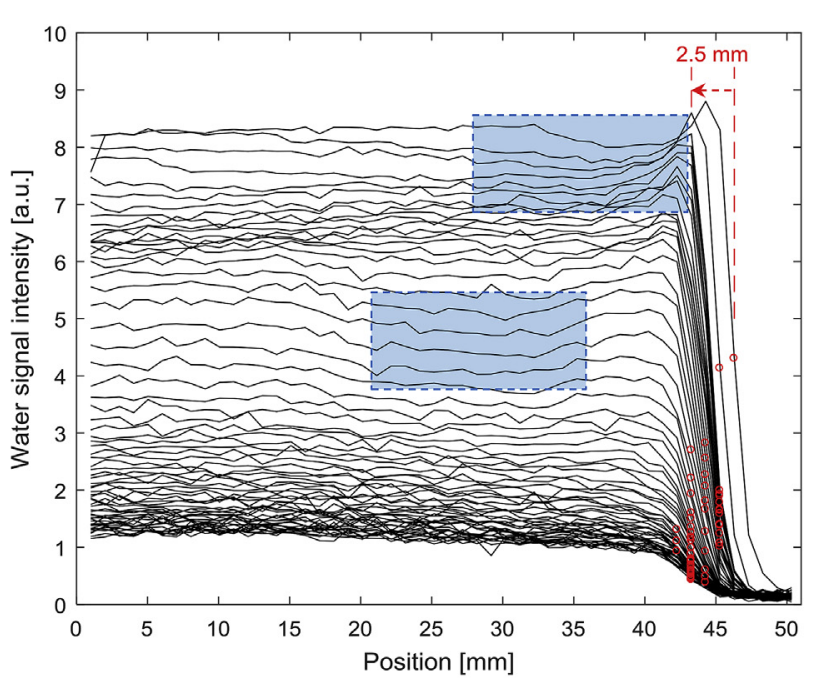

$\mathbf{A}_{\mathbf{e}}$

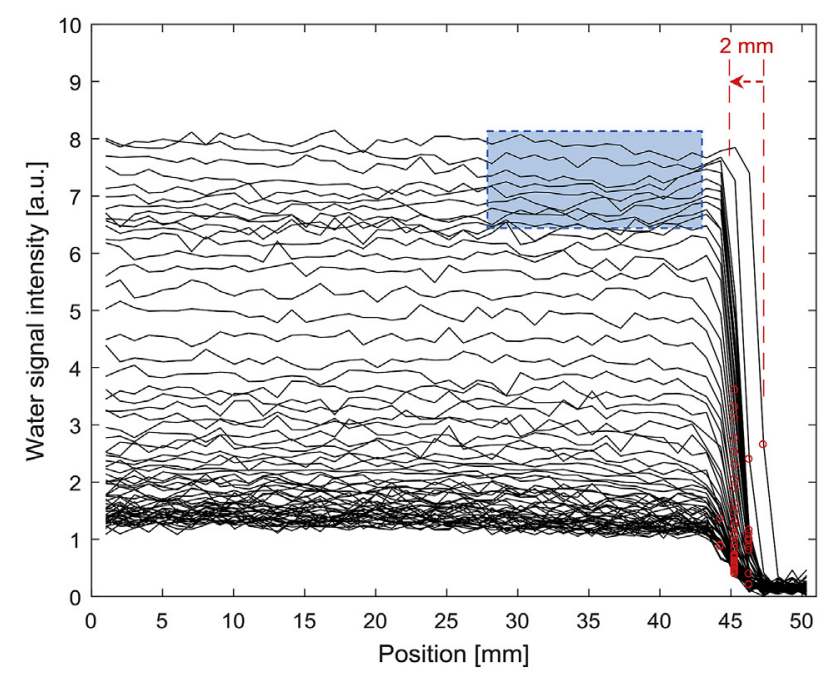

$\mathbf{B}_{\mathrm{e}}$

Fig. 2. Total water signal intensity [a.u] along the height of the specimen [mm] with the inflection points $\left(^{\circ}\right)$ used to calculate the plastic settlement. The measurements are taken at $44 \mathrm{~min}$ intervals for a total time of $48 \mathrm{~h}$.

relative humidity and overall conditions. It is as if the drying is not influencing the hardening of the interior of the specimen. The results even correspond to hydration in sealed conditions, when comparing to previously published results on the same samples [32]. In SAP systems, the total water signal is also as high as for the R0.354 specimen. This is due to the stored water in the SAPs, which corresponds to the additional 0.054 water-to-cement ratio. The effective water-to-cement ratio for the cementitious matrix is the same as for the R0.30 mixture. Only some minor influences due to drying are seen in the total water signal curves. These are found in the blue regions as shown in Fig. 2. Water is partially used during plastic setting as the cementitious matrix is not set yet. This is seen in the first $10-15 \mathrm{~mm}$ from the surface. In time, the curves become flat and internal curing takes over. At $48 \mathrm{~h}$ of testing, i.e. the lower curves, the water profiles are uniform along the height of the specimen. This is different compared to the tilted curves for the reference samples. This hints to the partial mitigation of plastic shrinkage.

From the values for the plastic settlement (not taking into account possible interior drying fronts) as determined by the inflection points, more plastic settlement is found in the reference specimens ( 3 and $4.5 \mathrm{~mm}$ for the R0.30 and R0.354 mixture, respectively) compared to the SAP specimens ( 2.5 and $2 \mathrm{~mm}$ for Ae and Be, respectively). The higher the water-to-cement ratio, the higher is the plastic settlement. In contrast to the results found by Dudziak and Mechtcherine, i.e. that the capillary pressure and the plastic deformations were reduced in the SAP mixtures, but the settlement deformation increased [23], the plastic settlement was reduced but still present. Furthermore, cracking was visually observed after NMR testing in the reference samples, which was not the case for the SAP specimens. In the latter, only some minor microcracking near the surface was observed but it was not noteworthy. This will be discussed in section 3.3.

\subsection{Entrained water signal versus free water signal in SAP mixtures}

By means of CPMG tests and FLI, relaxation times $\mathrm{T}_{2}$ as a spectrum were obtained. This spectrum shows different peaks in $\mathrm{T}_{2}$ which can be attributed to different water states, i.e. the free water and the water signal by the SAPs. An example of these peaks and the computation on analogous specimens can be found in Fig. 3 , at $5 \mathrm{~mm}$ below the drying surface. A distinct peak in $\mathrm{T}_{2}$ relaxation time in all systems is attributed to free water. In reference samples, this peak quickly disappears due to 


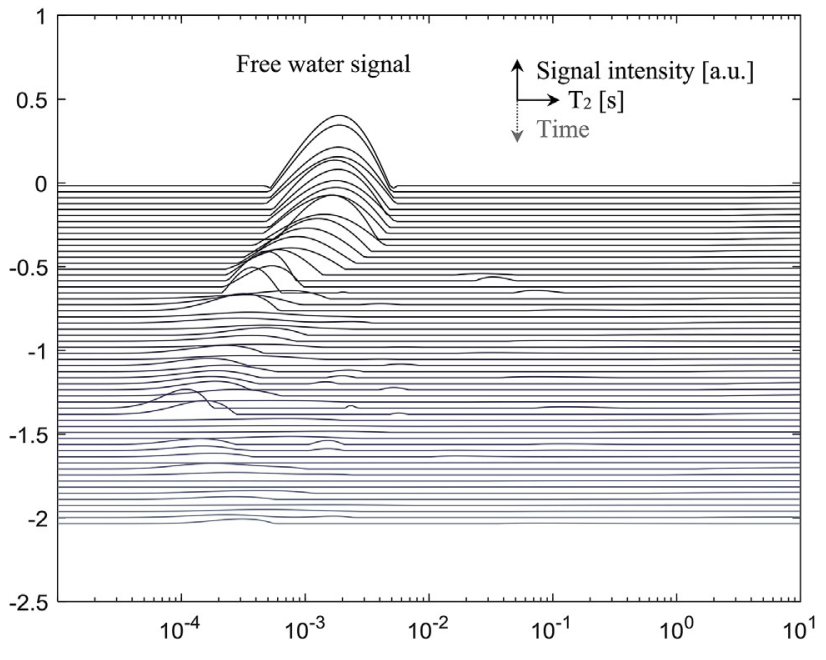

R0.30

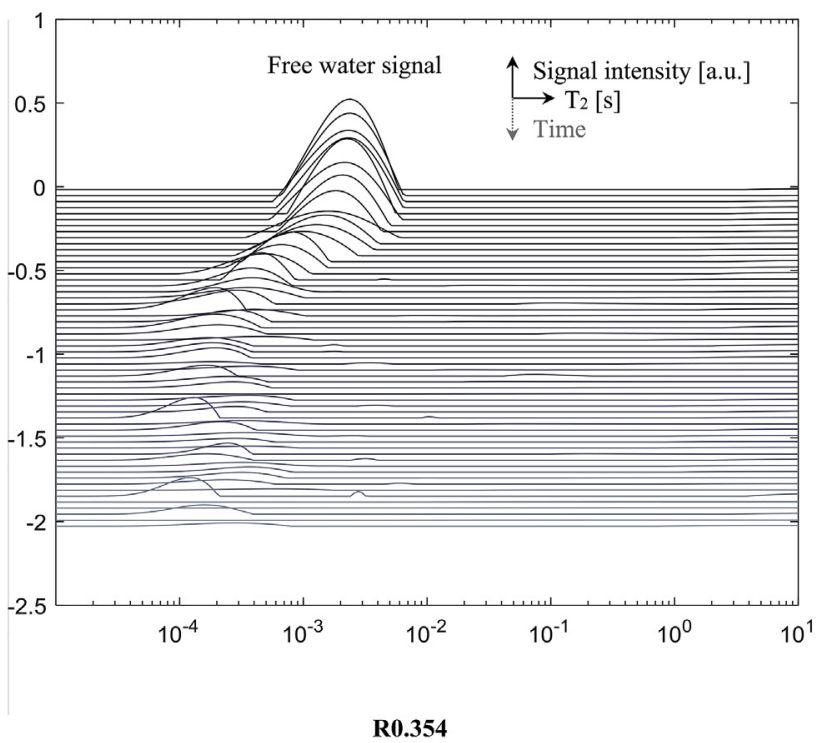

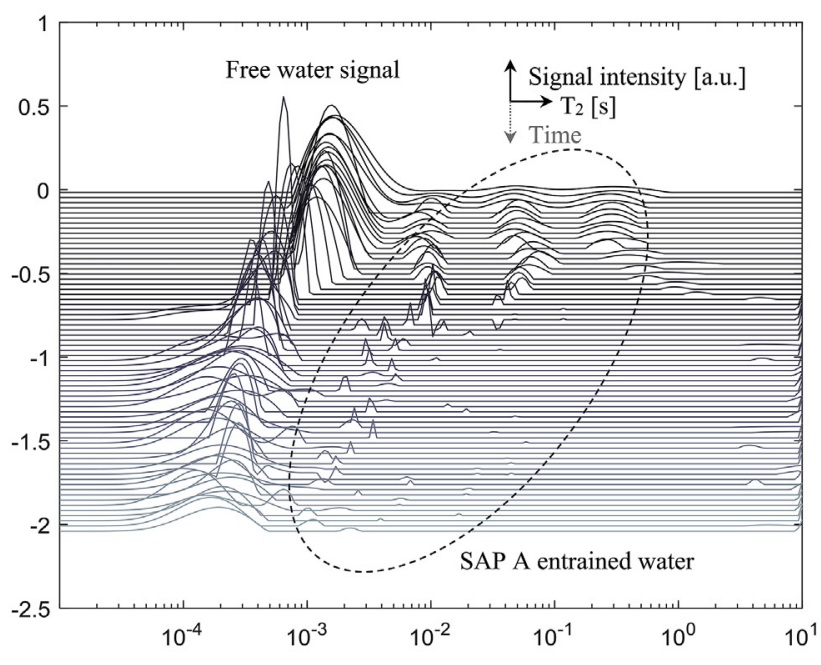

Ae

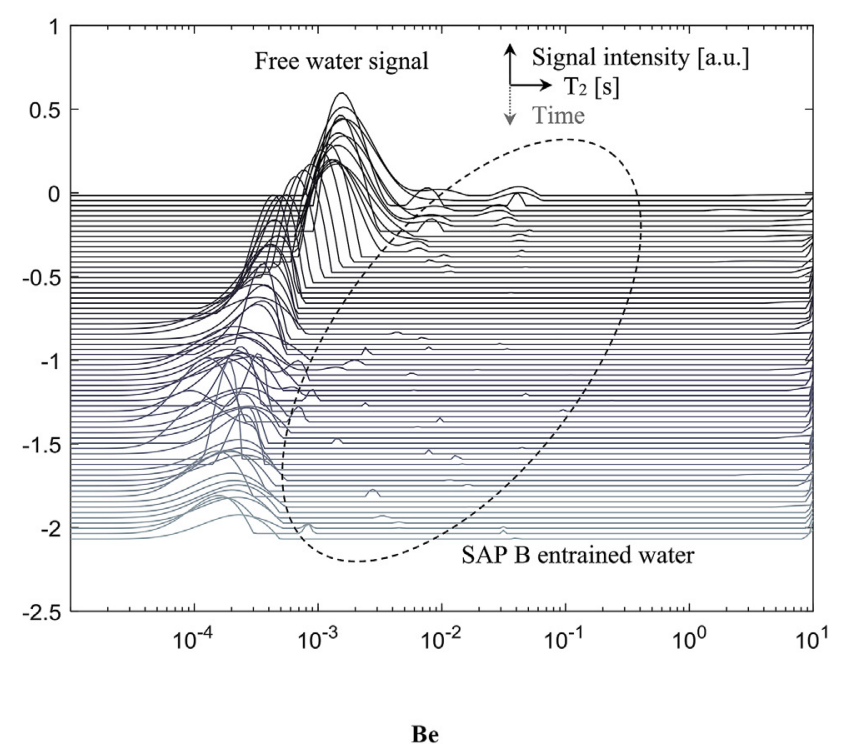

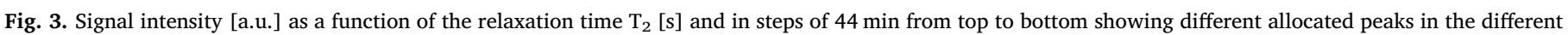
studied specimens, close to the drying surface.

the harsh drying conditions. In the SAP systems, additional peaks are allocated to SAP-entrained water. This water is stored in the SAP particles and can be released for internal curing. In that way, as the $T_{2}$ is different, the water kinetics from the SAPs towards the cementitious matrix could be studied in detail as a function of time. It is clearly seen that also water from the SAP pores is consumed, especially for the SAP B systems as the SAP-peaks disappear in time.

The signal intensities for the entrained water and the free water could be compared (Fig. 4). In this figure both signal fractions are plotted relative to each other. The black curves are the ones closest to the drying surface and are prone to plastic shrinkage. The red curves are closer to the interior of the sample itself. For comparative reasons, all other curves $(0-40 \mathrm{~mm}$ and $0-41 \mathrm{~mm}$ for the SAP A and SAP B specimen, respectively) are shown as red area comprising all curves found, showing the same behaviour. This thus is the boundary for the internal hydration of the samples.

The overall theoretical relation is depicted (30/5.4 inclination) as a straight line, as found by using the Powers and Brownyard model [33]. In this model, an amount of 0.054 additional water-to-cement ratio is required to mitigate autogenous shrinkage of a reference system with a water-to-cement ratio of 0.30 . During hardening, the signal is moving from the top right to the origin in the bottom left, as water is consumed (red arrow). The theoretical water as found by the Powers and Brownyard model is stored in the SAPs. As can be seen, as the signals travel in time from the theoretical point on the top-right to the origin, all expected internal curing water was stored in the SAPs and the amounts of SAP added are the correct ones. Other amounts of entrained water would lead to curves starting elsewhere. There thus was a good correlation between these theoretical expected values and the values obtained with NMR.

Due to plastic settlement, SAP A particles are packed closer together, leading to the higher signal value of total entrained water intensity near the surface (black arrow). The free water signal decreases rapidly and free water is consumed together with a release of the entrained water. The SAP seems to release little amount of entrained water in the beginning and store it within its structure. This water is then used to counteract the evaporation due to the imposed drying conditions once the material begins to set. This is seen as a more or less horizontal line in the curve, where the entrained-water signal is decreasing at approximately constant free water signal. The curves then move towards a normal hydration curve for a SAP A system. For $A_{e}$, just below $2.5 \mathrm{~mm}$ inwards (i.e. the red area), the cement paste is hardening 


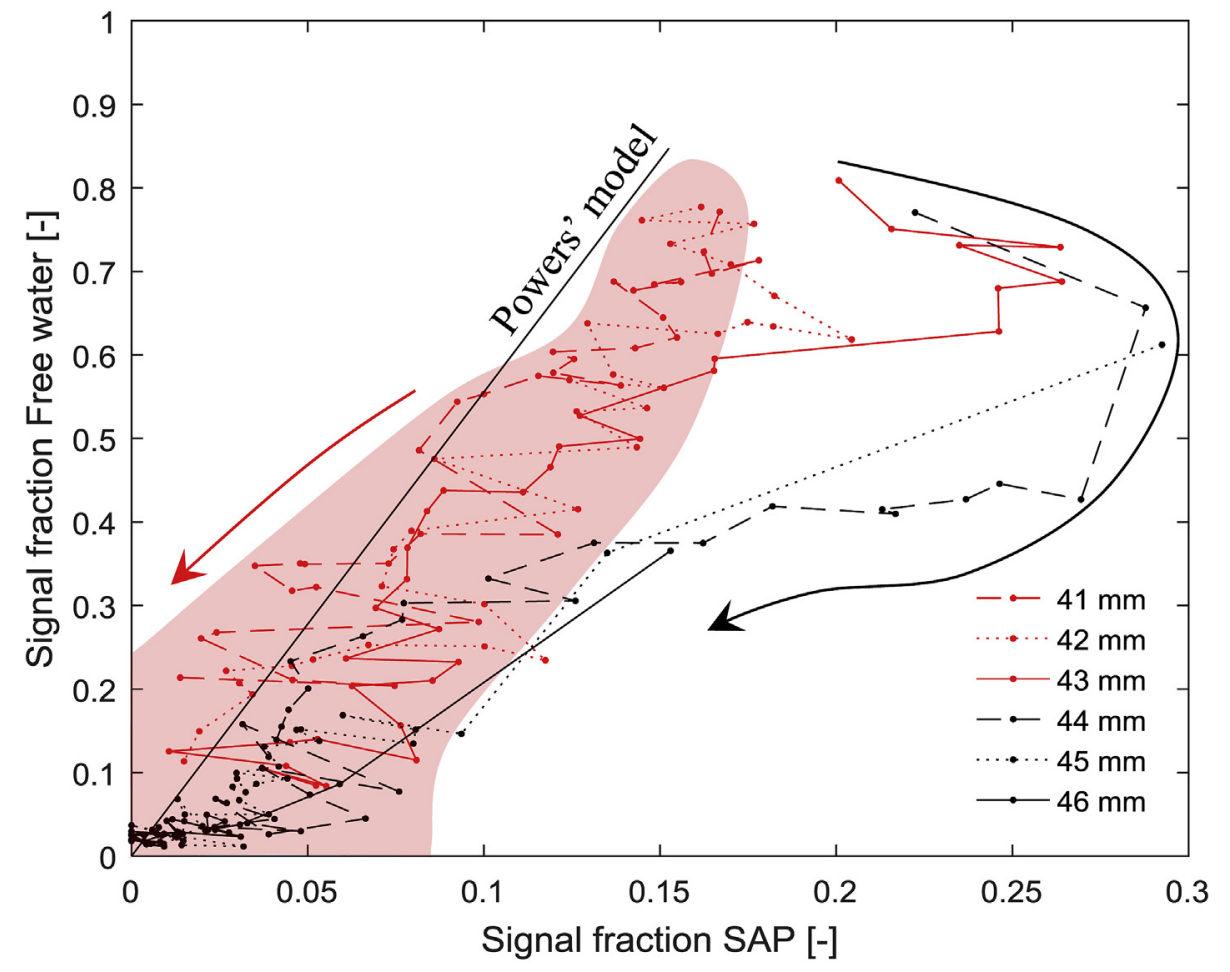

$\mathbf{A}_{\mathbf{e}}$

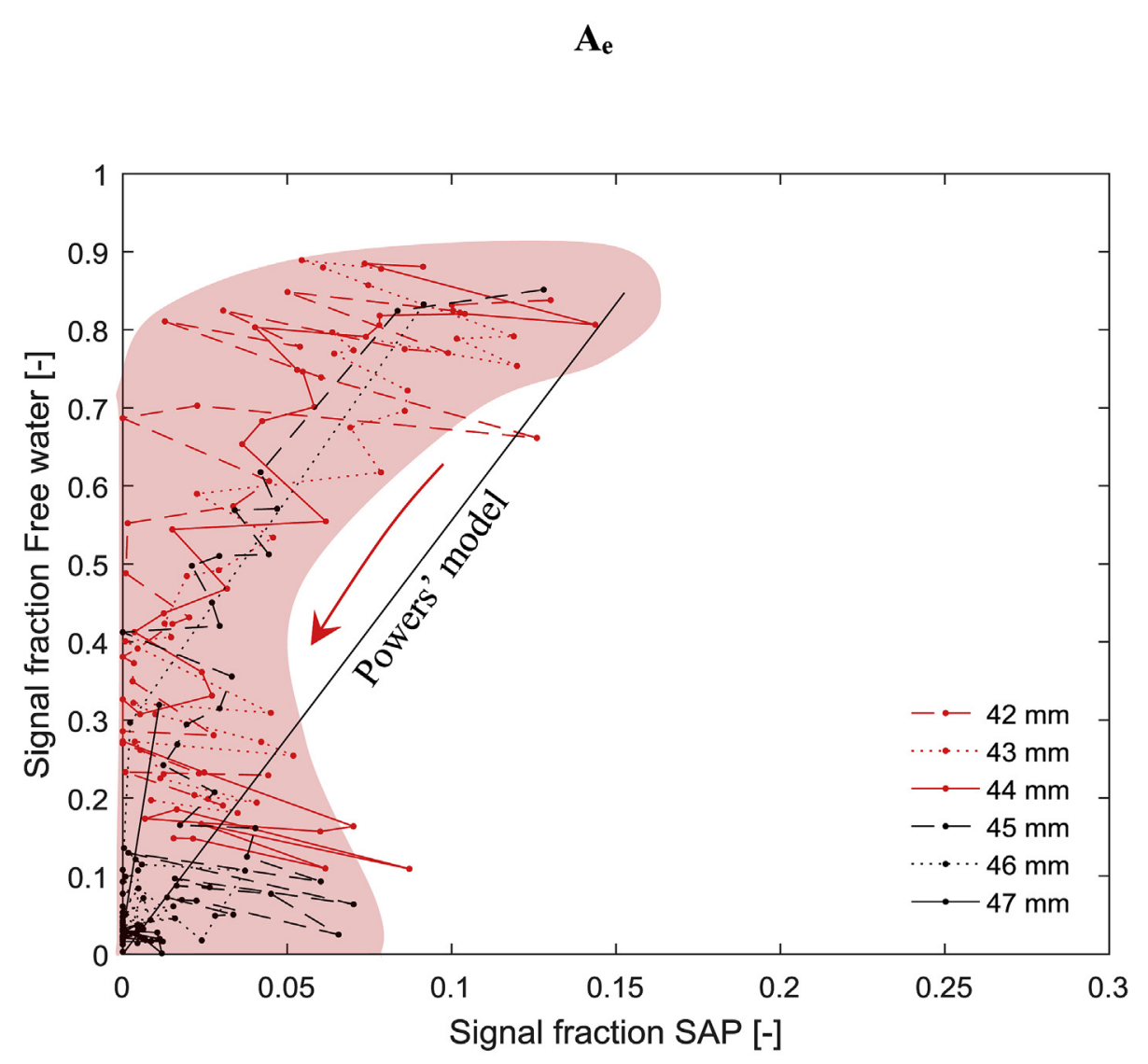

Fig. 4. Comparison of the signal fraction of entrained water in the SAPs [-] to the signal fraction of free water $[-]$ for the $A_{e}$ and $B_{e}$ mixtures showing a different kind of behaviour towards water kinetics near the drying surface. The arrows show the evolution in time of the curves in the top $5 \mathrm{~mm}$ of the sample and the red area the boundaries of the signals below $5 \mathrm{~mm}$ of the drying surface. The initial sample surface is positioned at $46 \mathrm{~mm}$ for $A_{e}$ and $47 \mathrm{~mm}$ for $\mathrm{B}_{\mathrm{e}}$. The theoretical line following Powers' model is also shown as a solid line. (For interpretation of the references to colour in this figure legend, the reader is referred to the Web version of this article.)

$\mathbf{B}_{\mathrm{e}}$

as if no drying is occurring. The SAPs thus seem to act as protective layer and internal curing reservoir within the cement paste.

SAP B, however, seems to release its water prematurely due to the larger particle size. They are less in total number and have a smaller surface area exposed to the drying matrix compared to the smaller SAP A. The plastic settlement, however, is still less compared to the 

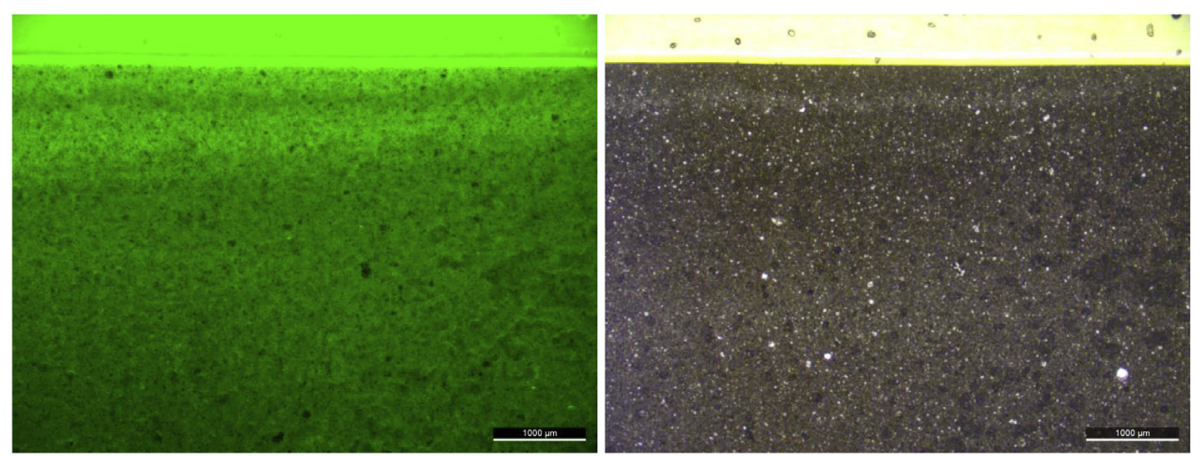

R0.30
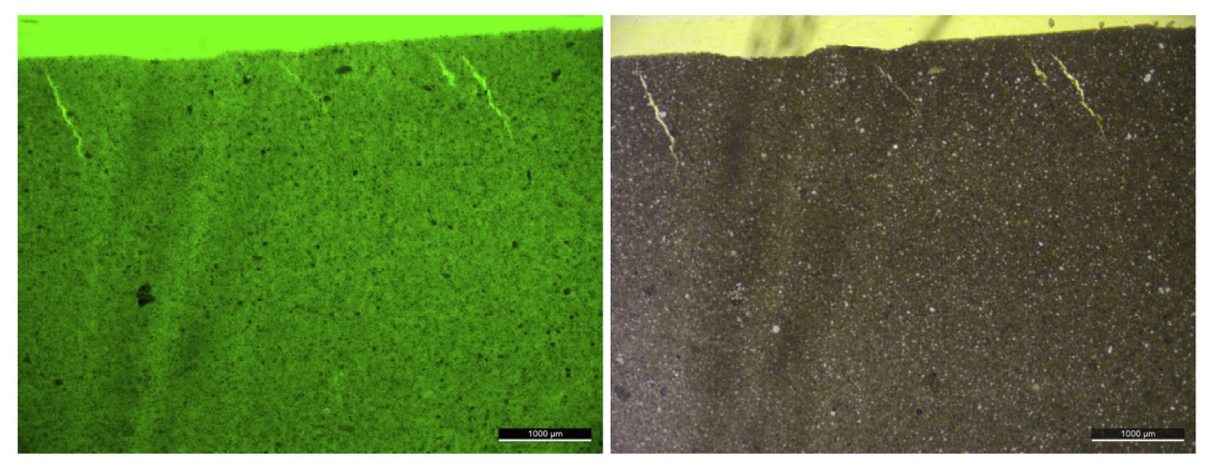

R0.354

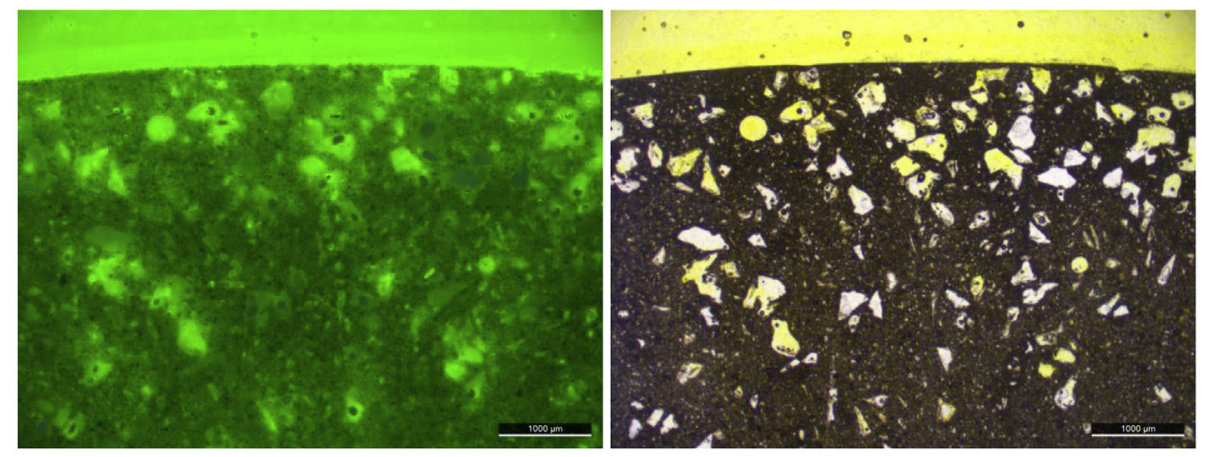

Ae

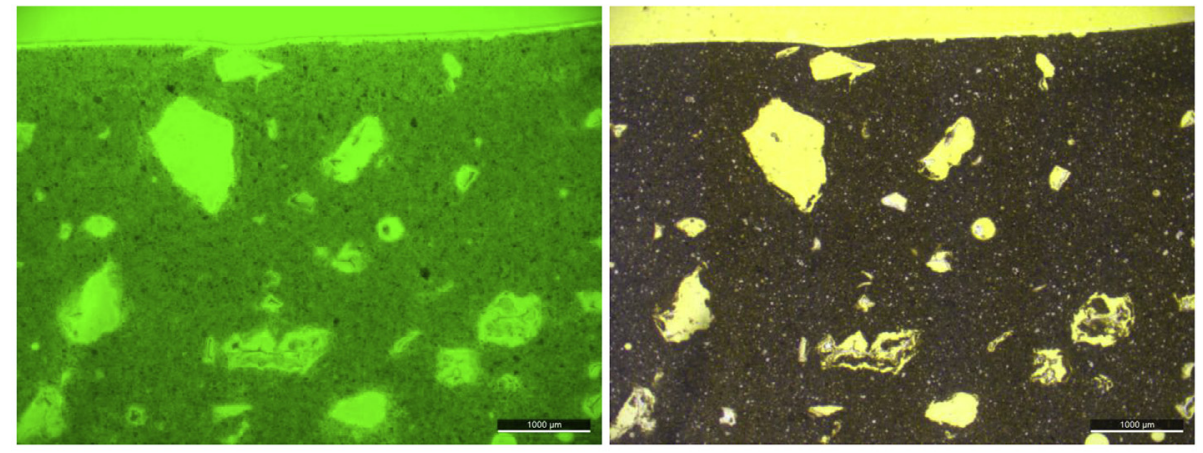

Be

Fig. 5. Thin sections with fluorescent light (left) and through-going normal light (right) showing the microstructural details for all studied mixtures. In the R0.354 microcracking is observed. The SAP macro pores are clearly seen for the SAP A and SAP B mixtures. The scale bar amounts to $1000 \mu \mathrm{m}$.

settlement of the reference samples. The water stored in the SAP B systems is quickly consumed and used in the overall cementitious system. When looking at the $47 \mathrm{~mm}$ line, one notices a quick consummation of both free water and SAP stored water. This is due to the quick drying at the surface.

SAP A is also able to mitigate autogenous shrinkage, as we have 
shown before [17]. This internal curing together with maintaining the internal relative humidity was also studied by means of NMR measurements in our earlier work [32]. The same overall trend in signal fractions of free water and of entrained water stored in the SAP was found. For SAP B, it seemed that the polymer was not as effective to mitigate autogenous shrinkage as compared to the ideal smaller SAP. The same conclusions can here be drawn in terms of the plastic shrinkage.

\subsection{Thin-section analysis}

The thin-sections for all studied mixtures are shown in Fig. 5. On the left-hand side the fluorescent images are shown and on the right-hand side the normal through-going light micrographs of the specimen at the same location and with the same magnification.

In reference samples, a densification of and change in the cementitious matrix is seen in the upper $700 \mu \mathrm{m}$ from the surface. This is clear in the R0.30 specimen when studying the through-going light image. During testing, partial carbonation may also have taken place. Some minor cracking was observed and this cracking was more prominent for the R0.354 mixture. Clear drying cracks could be observed and these were due to plastic shrinking. Some partial densification was seen in the area of $10-15 \mathrm{~mm}$ below the surface due to the consummation of free water which diffused towards the surface as the surface was imposed to harsh drying conditions. This was the effect also seen in Fig. 2 for R0.354 (blue region).

When studying the SAP specimens, less densification can be noticed. The cementitious matrix resembles the inner matrix of the R0.30 mixture, if the macro pores are not taken into consideration. This is due to the same effective water-to-cement ratio $[30,36]$. As this ratio is the same, the same overall microstructure was expected. If the theoretical absorption of mixing water by the SAPs was not the same as would occur in the specimen, the cementitious matrix would have had either a higher or lower amount of mixing water when the absorption by the SAPs was lower or higher than expected. This would be seen as a difference in intensity in the micrographs, which was not observed.

SAP A was packed closer together at the surface due to the partial release of mixing water due to the harsh drying conditions. This functional layer upon plastic shrinkage was also expected from the results found in Fig. 4. SAP B, which was larger, did not accumulate at the surface to protect against plastic shrinkage. This also corresponds to the effects studied in Fig. 4. By means of image analysis, the pore sizes of SAP could be investigated. Theoretically, the size should be $257 \mu \mathrm{m}$ and $981 \mu \mathrm{m}$ for SAP A and SAP B, respectively, as calculated based on their swelling capacity of mixing water and the initial dry size. This average size $(\mathrm{n}=100)$ was found in the bulk material of the specimens; $253 \pm 66 \mu \mathrm{m}$ and $891 \pm 194 \mu \mathrm{m}$ for SAP A and SAP B, respectively. The amount is thus the correct one as the cementitious matrix is formed at final setting, thus maintaining the size of the macro pores. This amount corresponds to the theoretical amount based on the needed water for internal curing as determined by the Powers and Brownyard model, as was previously discussed.

\section{Conclusions}

Based on the findings of the research on the mitigation of plastic shrinkage by SAPs as studied by means of NMR following conclusions can be drawn:

- In reference systems, there is clear plastic shrinkage and plastic shrinkage cracking due to the applied air current. Water from the interior is partially used to counteract the loss due to plastic shrinkage drying. This was seen as a local decrease in total water content $10-15 \mathrm{~mm}$ below the drying surface.

- The plastic shrinkage settlement is lower in SAP systems compared to reference systems. However, plastic shrinkage is still present due to the harsh drying conditions but SAPs seem to be a promising admixture to partially mitigate plastic shrinkage.

- SAP A, which is smaller compared to SAP B, is able to mitigate plastic shrinkage better by providing its stored water towards the cementitious matrix during harsh drying conditions when a cement paste is hardening. In the interior of the samples, hydration occurs like in sealed conditions.

- Near the drying surface, the free water is consumed first, followed by a gradual release of the stored water in SAP A, thus effectively mitigating plastic shrinkage.

- SAP B releases its stored water quickly when exposed to harsh drying conditions. The bigger SAP B is less suitable to counteract plastic shrinkage as the larger particles are less present in the overall cementitious matrix.

\section{Acknowledgements}

As a Postdoctoral Research Fellow of the Research FoundationFlanders (FWO-Vlaanderen), D. Snoeck would like to thank the foundation for the financial support (12J3617 N) and for the research stay as Guest Researcher at the Technical University of Eindhoven (TU/e) (V420617 N). The staff of TU/e is gratefully acknowledged for the support and the discussions. The authors want to thank Dr. A. Assmann and Dr. G. Herth from BASF for providing SAP A and SAP B.

\section{Appendix A. Supplementary data}

Supplementary data related to this article can be found at http://dx. doi.org/10.1016/j.cemconcomp.2018.06.019.

\section{References}

[1] F.L. Buchholz, A.T. Graham, Modern Superabsorbent Polymer Technology, WileyVCH, New-York, 1998.

[2] 225-SAP, Application of superabsorbent polymers (SAP) in concrete construction, in: V. Mechtcherine, H.W. Reinhardt (Eds.), RILEM State-of-the-Art Report Prepared by Technical Committee 225-SAP, 2012, p. 165.

[3] V. Mechtcherine, E. Secrieru, C. Schröfl, Effect of superabsorbent polymers (SAPs) on rheological properties of fresh cement-based mortars - development of yield stress and plastic viscosity over time, Cement Concr. Res. 67 (2015) 52-65.

[4] V. Mechtcherine, C. Schröfl, M. Wyrzykowski, M. Gorges, D. Cusson, J. Margeson, N. De Belie, D. Snoeck, K. Ichimiya, S.-I. Igarashi, V. Falikman, S. Friedrich, J. Bokern, P. Kara, P. Lura, A. Marciniak, H.-W. Reinhardt, S. Sippel, A.B. Ribeiro, J. Custódio, G. Ye, H. Dong, J. Weiss, Effect of superabsorbent polymers (SAP) on the freeze-thaw resistance of concrete: results of a RILEM interlaboratory test, Mater. Struct. 50 (14) (2017) 1-19.

[5] S. Mönnig, P. Lura, Superabsorbent polymers - an additive to increase the freezethaw resistance of high strength concrete, in: C.U. Grosse (Ed.), Adv. Constr. Mater, Springer Berlin Heidelberg, Berlin, 2007, pp. 351-358.

[6] H.X.D. Lee, H.S. Wong, N.R. Buenfeld, Potential of superabsorbent polymer for selfsealing cracks in concrete, Adv. Appl. Ceram 109 (5) (2010) 296-302.

[7] H.X.D. Lee, H.S. Wong, N.R. Buenfeld, Self-sealing of cracks in concrete using superabsorbent polymers, Cement Concr. Res. 79 (2016) 194-208.

[8] D. Snoeck, S. Steuperaert, K. Van Tittelboom, P. Dubruel, N. De Belie, Visualization of water penetration in cementitious materials with superabsorbent polymers by means of neutron radiography, Cement Concr. Res. 42 (8) (2012) 1113-1121.

[9] D. Snoeck, K. Van Tittelboom, N. De Belie, S. Steuperaert, P. Dubruel, The use of superabsorbent polymers as a crack sealing and crack healing mechanism in cementitious materials, in: M.G. Alexander, H.-D. Beushausen, F. Dehn, P. Moyo (Eds.), 3rd International Conference on Concrete Repair, Rehabilitation and Retrofitting, Cape Town, 2012, pp. 152-157.

[10] D. Snoeck, Self-healing and Microstructure of Cementitious Materials with Microfibres and Superabsorbent Polymers, Struct. Eng, Ghent University, Ghent, 2015, p. 364.

[11] D. Snoeck, N. De Belie, Repeated autogenous healing in strain-hardening cementitious composites by using superabsorbent polymers, J. Mater. Civ. Eng. (2015) 1-11 04015086.

[12] D. Snoeck, N. De Belie, From straw in bricks to modern use of microfibres in cementitious composites for improved autogenous healing - a review, Construct. Build. Mater. 95 (2015) 774-787.

[13] D. Snoeck, J. Dewanckele, V. Cnudde, N. De Belie, X-ray computed microtomography to study autogenous healing of cementitious materials promoted by superabsorbent polymers, Cement Concr. Compos. 65 (2016) 83-93.

[14] D. Snoeck, K. Van Tittelboom, S. Steuperaert, P. Dubruel, N. De Belie, Self-healing cementitious materials by the combination of microfibres and superabsorbent polymers, J. Intell. Mater. Syst. Struct. 25 (1) (2014) 13-24. 
[15] O.M. Jensen, P.F. Hansen, Water-entrained cement-based materials I. Principles and theoretical background, Cement Concr. Res. 31 (4) (2001) 647-654.

[16] O.M. Jensen, P.F. Hansen, Water-entrained cement-based materials II. Experimental observations, Cement Concr. Res. 32 (6) (2002) 973-978.

[17] D. Snoeck, O.M. Jensen, N. De Belie, The influence of superabsorbent polymers on the autogenous shrinkage properties of cement pastes with supplementary cementitious materials, Cem. Concr. Res. 74 (2015) 59-67.

[18] V. Mechtcherine, M. Gorges, C. Schröfl, A. Assmann, W. Brameshuber, V. Bettencourt Ribeiro, D. Cusson, J. Custódio, E. Fonseca da Silva, K. Ichimiya, S. Igarashi, A. Klemm, K. Kovler, A. Lopes, P. Lura, V.T. Nguyen, H.W. Reinhardt, R.D. Toledo Filho, J. Weiss, M. Wyrzykowski, G. Ye, S. Zhutovsky, Effect of internal curing by using superabsorbent polymers (SAP) on autogenous shrinkage and other properties of a high-performance fine-grained concrete: results of a RILEM roundrobin test, TC 225-SAP, Mater. Struct. 47 (3) (2014) 541-562.

[19] E. Boghossian, L.D. Wegner, Use of flax fibres to reduce plastic shrinkage cracking in concrete, Cement Concr. Compos. 30 (10) (2008) 929-937.

[20] F.H. Wittmann, On the action of capillary pressure in fresh concrete, Cement Concr. Res. 6 (1976) 49-56.

[21] V. Slowik, M. Schmidt, R. Fritzsch, Capillary pressure in fresh cement-based materials and identification of the air entry value, Cement Concr. Compos. 30 (2008) $557-565$.

[22] R. Combrinck, W.P. Boshoff, Typical plastic shrinkage cracking behaviour of concrete, Mag. Concr. Res. 65 (8) (2013) 486-493.

[23] L. Dudziak, V. Mechtcherine, Enhancing early-age resistance to cracking in highstrength cement based materials by means of internal curing using super absorbent polymers, in: W. Brameshuber (Ed.), International RILEM Conference on Material Science, RILEM Publications S.A.R.L, Aachen, 2010, pp. 129-139.

[24] A.C.A. Muller, K.L. Scrivener, A.M. Gajewicz, P.J. McDonald, Densification of C-S-H measured by ${ }^{1} \mathrm{H}$ NMR relaxometry, Phys. Chem. C 117 (1) (2013) 403-412.

[25] S. Roels, J. Carmeliet, H. Hens, O. Adan, H. Brocken, R. Verny, Z. Pavlik, T. Ellisa, C. Hall, K. Kumaran, L. Pel, R. Plagge, A comparison of different techniques to quantify moisture content profiles in porous building materials, J. Build. Phys. 27 (4) (2004) 361-376.

[26] R.M.E. Valckenborg, L. Pel, K. Hazrati, K. Kopinga, J. Marchand, Pore water distribution in mortar during drying as determined by NMR, Mater. Struct. 34 (10) (2001) 599-604.
[27] K.R. Brownstein, C.E. Tarr, Importance of classical diffusion in NMR studies of water in biological cells, Phys. Rev. 19 (1979) 2446-2453.

[28] K. Friedemann, F. Stallmach, J. Kärger, NMR diffusion and relaxation studies during cement hydration - a non-destructive approach for clarification of the mechanism of internal post curing of cementitious materials, Cement Concr. Res. 36 (5) (2006) $817-826$.

[29] N. Nestle, A. Kühn, K. Friedemann, C. Horch, F. Stallmach, G. Herth, Water balance and pore structure development in cementitious materials in internal curing with modified superabsorbent polymers studied by NMR, Microporous Mesoporous Mater. 125 (1-2) (2009) 51-57.

[30] D. Snoeck, D. Schaubroeck, P. Dubruel, N. De Belie, Effect of high amounts of superabsorbent polymers and additional water on the workability, microstructure and strength of mortars with a water-to-cement ratio of 0.50, Construct. Build. Mater. 72 (2014) 148-157.

[31] H.W. Reinhardt, A. Assmann, Enhanced durability of concrete by superabsorbent polymers, in: A.M. Brandt, J. Olek, I.H. Marshal (Eds.), International Symposium Brittle Matrix Composites 9, Woodhead Publishing, Warsaw, 2009, pp. 291-300.

[32] D. Snoeck, L. Pel, N. De Belie, The water kinetics of superabsorbent polymers during cement hydration and internal curing visualized and studied by NMR, Sci. Rep. 7 (9514) (2017) 1-14.

[33] T.C. Powers, T.L. Brownyard, Studies of the Physical Properties of Hardened Portland Cement Paste, Portland Cement Association, Research Laboratories, Cornell, 1948.

[34] C. Schröfl, D. Snoeck, V. Mechtcherine, A review of characterisation methods for superabsorbent polymer (SAP) samples to be used in cement-based construction materials - report of the RILEM TC 260-RSC, Mater. Struct. 50 (197) (2017) 1-19.

[35] D. Snoeck, N. De Belie, Effect of superabsorbent polymers, superplasticizer and additional water on the setting of cementitious materials, Int. J. of 3R's 5 (3) (2015) 721-729.

[36] D. Snoeck, L.F. Velasco, A. Mignon, S. Van Vlierberghe, P. Dubruel, P. Lodewyckx, N. De Belie, The effects of superabsorbent polymers on the microstructure of cementitious materials studied by means of sorption experiments, Cem. Concr. Res. 77 (2015) 26-35.

[37] Y.Q. Song, L. Venkataramanan, M.D. Hürlimann, M. Flaum, P. Frulla, C. Straley, $\mathrm{T}(1)-\mathrm{T}(2)$ correlation spectra obtained using a fast two-dimensional Laplace inversion, J. Magn. Reson. 154 (2) (2002) 261-268. 